\title{
Immunological Properties of the Primer-independent Glucosyltransferase of Streptococcus mutans Serotypes $d$ and $g$
}

\author{
By YOSHIHISA YAMASHITA, TOSHIYUKI SHIGEOKA, \\ NOBUHIRO HANADA AND TADAMICHI TAKEHARA* \\ Department of Preventive Dentistry, Kyushu Dental College, Kokurakitaku, Kitakyushu 803, \\ Japan
}

(Received 18 December 1987)

\begin{abstract}
Streptococcus mutans serotype $g$ secretes at least three kinds of glucosyltransferase with different enzymological and immunological properties. One of them is a primer-independent enzyme and seems to be the source of primer for the others, both of which are primer-dependent enzymes. Recently, we purified the primer-independent enzyme, the third glucosyltransferase in this group from $S$. mutans strain AHT-k serotype $g$. In the present study, we examined the specificity of the antiserum against the primer-independent glucosyltransferase using extracellular cultureconditioned fluids of many strains of the various serotypes of $S$. mutans. The antiserum crossreacted with the extracellular culture fluids from strains of serotypes $d$ and $a$, in addition to serotype $g$, but not with those of other serotypes, indicating that the primer-independent glucosyltransferase is secreted by the $S$. sobrinus and $S$. cricetus, but not by $S$. mutans and $S$. rattus. The antiserum did not completely inhibit the activity of the enzyme, even at more than twofold antibody excess, determined by indirect precipitation with immobilized staphylococcal protein A.
\end{abstract}

\section{INTRODUCTION}

Streptococcus mutans secretes several kinds of glucosyltransferase which are important in cariogenicity (Gibbons \& Banghart, 1967; Gibbons, 1968; Gibbons \& Nygaard, 1968; Critchley et al., 1976). The various strains of $S$. mutans can be separated into seven or eight serotypes according to their cell surface antigenicities (Bratthall, 1970; Perch et al., 1974; Beighton et al., 1981), the classification series ranging from serotypes $a$ to $g$ and/or $h$. These serotypes can in turn be classified into four groups according both to the specificities of their enzymes in extracellular polysaccharide synthesis (Mukasa, 1986; Kametaka et al., 1987) and to other biochemical properties (Coykendall, 1977; Shklair \& Keene, 1974). Thus, serotypes $d, g$ and/or $h$ ( $S$. sobrinus) form one group, serotype $a(S$. cricetus) another, serotypes $c, e$ and $f(S$. mutans) a third, and serotype $b$ ( $S$. rattus) the fourth group. The mechanism of synthesis of extracellular polysaccharides in each group seems to be different.

Three kinds of glucosyltransferase have been purified from $S$. mutans serotype $g$; one is primer-independent water-soluble glucan synthase (McCabe, 1985), and the others are primerdependent glucosyltransferase (Fukui et al., 1981; Shimamura et al., 1982). The former is thought to be the supplier of primer for the other two, and to have a significant role in the formation of $S$. mutans serotype $g$ extracellular polysaccharide. Recently, we purified this enzyme, the third glucosyltransferase to be isolated from $S$. mutans strain AHT-k serotype $g$ (Hanada et al., 1987).

In the present study, using antiserum against this enzyme, we examined the distribution of the enzyme in eight strains of $S$. mutans of various serotypes, and studied the effects of the antiserum on its activity. 


\section{METHODS}

Materials. All strains of $S$. mutans used in the present study were kindly provided by Dr M. Inoue, Kagoshima University Dental School, Kagoshima, Japan. Affi-gel protein A MAPS-II kit, protein A cellulofine and Schiff's reagent were purchased from Bio-Rad, Seikagaku Kogyo (Tokyo, Japan) and Merck, respectively. All other chemicals were of analytical grade.

Preparation of crude enzyme solution. The following strains of $S$. mutans were grown anaerobically, as previously described (Takehara et al., 1984). HS-1 (serotype $a$ ), BHT (serotype $b$ ), Ingbritt (serotype $c$ ), OMZ176 (serotype $d$ ), B-14 (serotype $e$ ), OMZ175 (serotype $f$ ), and AHT-k and 6715 (serotype $g$ ). The extracellular culture-conditioned fluid of each strain was collected by centrifugation at $7000 \mathrm{~g}$ for $20 \mathrm{~min}$, and the resulting supernatant was precipitated with ammonium sulphate at $50 \%$ saturation. The precipitate was collected by centrifugation at $11000 \mathrm{~g}$ for $20 \mathrm{~min}$, suspended in $0.05 \mathrm{M}$-sodium acetate, $\mathrm{pH} \mathrm{6.0,} \mathrm{and} \mathrm{dialysed} \mathrm{against} \mathrm{the} \mathrm{same} \mathrm{buffer.} \mathrm{The}$ solutions thus obtained were used as crude enzyme preparations of each strain of $S$. mutans.

Purification of the primer-independent glucosyltransferase and preparation of antiserum. The primer-independent glucosyltransferase was purified to homogeneity from strain AHT-k of $S$. mutans, and antiserum was raised against the enzyme as previously described (Hanada et al., 1987). Control rabbit serum was obtained prior to injection of the antigen. The IgG fractions in the antiserum and control serum were purified using the Affi-gel

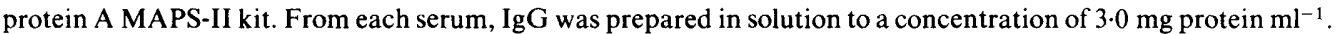

Enzyme assay. The activity of the primer-independent glucosyltransferase was determined by measuring the amount of water-soluble glucan synthesized in $0.1 \mathrm{~m}$-sodium acetate, $\mathrm{pH} 6.0$, containing $5 \%(\mathrm{w} / \mathrm{v})$ sucrose and 5 mm-sodium fluoride, as previously described (Hanada \& Takehara, 1987). However, centrifugation to remove water-insoluble glucan was omitted from the assay procedure, because purified enzyme did not synthesize any water-insoluble glucan.

Immunodiffusion analysis. Ouchterlony double immunodiffusion analysis (Ouchterlony, 1958) was done in $1 \%$ $(w / v)$ agarose gels.

Inhibitory effect of the antiserum. Purified enzyme $(0 \cdot 1 \mu \mathrm{g})$ was preincubated with various amounts of antiserum or control serum in $100 \mu \mathrm{l} 0 \cdot 1 \mathrm{M}$-sodium acetate, $\mathrm{pH} 6 \cdot 0$, containing $1 \mu \mathrm{g}$ bovine serum albumin (BSA), at $37^{\circ} \mathrm{C}$ for $30 \mathrm{~min}$. BSA was added to preincubation buffer in order to prevent inactivation of the enzyme during preincubation. After preincubation, the enzyme activity was determined in both antiserum- and control-serumcontaining solutions, and half of the solution containing antiserum was further incubated at $37{ }^{\circ} \mathrm{C}$ for 30 min in the same buffer containing $100 \mu \mathrm{l}$ protein A cellulofine and $1 \%$ Triton X-100. The enzyme activity was determined in the supernatant of the solution after centrifugation at $3000 \mathrm{~g}$ for $15 \mathrm{~min}$.

Paired double immunodiffusion analyses of purified and crude enzyme solutions obtained from strain AHT-k were done. After washing several times with $0 \cdot 1 \mathrm{M}$-sodium acetate, $\mathrm{pH} 6 \cdot 0$, one of each pair was immediately subjected to periodic acid Schiff staining, and the other of each pair to periodic acid Schiff staining after incubation with enzyme assay buffer at $37^{\circ} \mathrm{C}$ for $18 \mathrm{~h}$.

\section{RESULTS}

Fig. 1 shows the results of double immunodiffusion analyses of crude enzyme preparations from various strains of $S$. mutans, using the antiserum against the primer-independent glucosyltransferase of strain AHT-k. With crude enzyme preparations of strains AHT-k, 6715 and $O M Z 176$, the antiserum produced a single connecting line of precipitin, but formed a precipitin line spur with strain HS-1. In contrast, the antiserum did not cross-react with crude enzyme preparations from strains BHT, Ingbritt, B-14 (data not shown) or OMZ175 (data not shown).

Fig. 2 shows the inhibitory effects of the antiserum on enzyme activity. The antiserum only partially inhibited enzyme activity even when added in more than twofold excess. Thus, although addition of $2 \mu \mathrm{l}$ antiserum caused complete immunoreaction between the enzyme and antiserum, about half of the original enzyme activity remained, and addition of $5 \mu$ l antiserum had little further effect.

Fig. 3 shows the results obtained by periodic acid Schiff staining of the immunoprecipitin line, with or without preincubation in enzyme assay buffer. When preincubation was done, the precipitin line was clearly stained with periodic acid Schiff (Fig. 3a), but when it was not done the single connecting precipitin line of purified enzyme and crude enzyme solution could not be stained (Fig. 3b). 


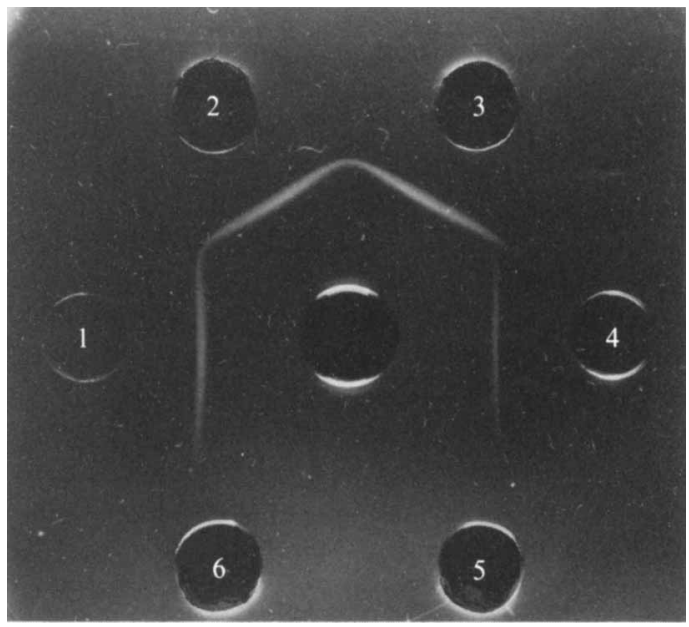

Fig. 1

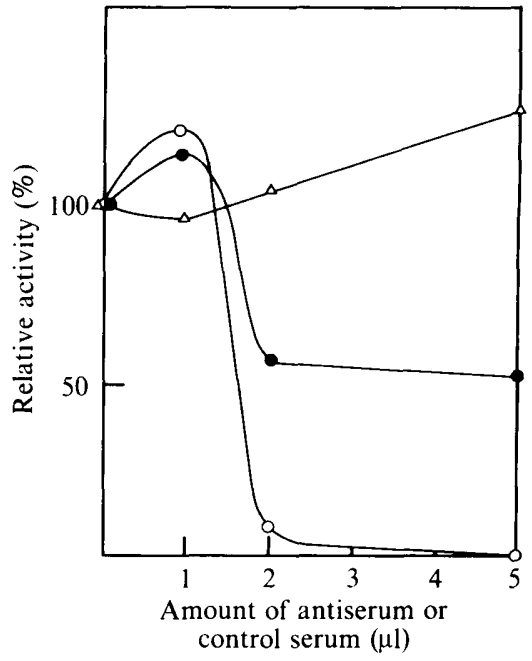

Fig. 2

Fig. 1. Double immunodiffusion analysis of crude enzyme preparations from various strains of $S$. mutans. The centre well contained antiserum $(20 \mu \mathrm{l})$ against the primer-independent glucosyltransferase from $S$. mutans strain AHT-k. Each outer well contained $400 \mu \mathrm{g}$ crude enzyme protein solution derived from one of the strains of $S$. mutans; 1, 6715; 2, AHT-k; 3, OMZ176; 4, HS-1; 5, Ingbritt; 6, BHT.

Fig. 2. Inhibitory effect of antiserum against $S$. mutans strain AHT-k primer-independent glucosyltransferase on purified enzyme activity. Relative enzyme activities are given as percentages, compared with the activity in the absence of antiserum or control serum. Details of the enzyme assay are described in Methods. Preincubated only with the antiserum; $\mathrm{O}$, incubated with protein $\mathrm{A}$ cellulofine after preincubation with antiserum; $\triangle$, preincubated with control serum.
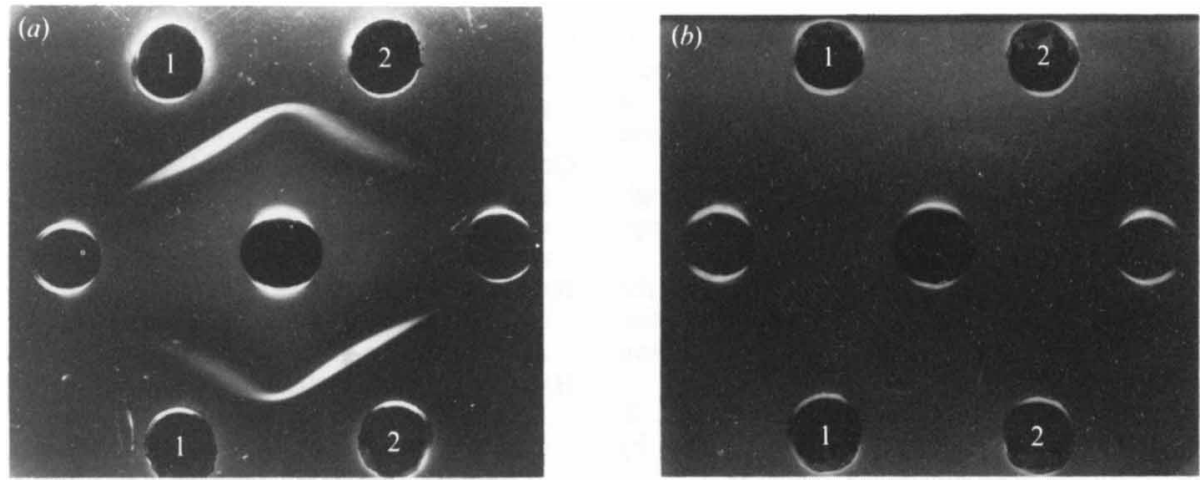

Fig. 3. Detection of enzyme activity in immunoprecipitation of primer-independent glucosyltransferase. Precipitin lines were allowed to form in double diffusion gels between antiserum $(20 \mu l)$ in the centre well, purified primer-independent glucosyltransferase $(2 \mu \mathrm{g}$, wells numbered 1$)$ and crude protein from $S$. mutans AHT-k $(200 \mu \mathrm{g}$, wells numbered 2$)$. Gel $a$ was subsequently incubated in the assay mixture for glucosyltransferase activity and gel $b$ was not, after which both gels were stained for carbohydrate with periodic acid Schiff reagent. Further details are given in Methods.

\section{DISCUSSION}

As a result of genetic (Coykendall, 1977) and biochemical (Shklair \& Keene, 1974) investigations the serotypes of $S$. mutans have been classified into separate species: $S$. sobrinus (serotypes $d$ and $g$ ), $S$. cricetus (serotype $a$ ), $S$. mutans (serotypes $c, e$ and $f$ ), and $S$. rattus (serotype $b$ ). Recently, following studies with the two primer-dependent glucosyltransferases, a primer-independent water-soluble glucan synthase was purified from strain AHT-k (Hanada et 
al., 1987) and from the 6715-13 mutant 27 (McCabe, 1985) of $S$. mutans serotype $g$, but its distribution in other serotypes of $S$. mutans remained unclarified. In the double immunodiffusion analyses, the enzyme/antiserum cross-reactions showed that the primer-independent glucosyltransferase of strain AHT-k was the same as that secreted by other strains of serotypes $d$, $g$ and $a$, but was different from that of the other serotypes (Fig. 1). However, the enzyme produced by serotypes $d$ and $g$ was immunologically slightly different from that of serotype $a$. These findings are similar to those obtained previously with the two primer-dependent glucosyltransferases (Fukui et al., 1974, 1983). The mechanisms of glucan synthesis are thought to differ from subspecies to subspecies, although those in $S$. sobrinus and $S$. cricetus have been found to be similar. In addition, immunological similarity between the glucosyltransferases of $S$. rattus and $S$. mutans was recently reported (Kumada et al., 1987). Thus, the mechanism of glucan synthesis in $S$. mutans must be resolved from at least two viewpoints.

There have been some reports on the effect of antiserum against the primer-dependent glucosyltransferases of $S$. mutans serotype $a, d$ and $g$ (Fukui et al., 1974, 1983; Linzer \& Slade, 1976), while until now there have been no studies using antiserum against the primerindependent enzyme. In the present study, such an antiserum was found to be unable to completely inhibit the activity of the enzyme, even though complete immunoreaction between the enzyme and the antiserum occurred (Fig. 2). In order to confirm this finding, the precipitin line formed in double immunodiffusion gels was treated with periodic acid Schiff reagent. Precipitin lines preincubated with the enzyme assay buffer could be stained (Fig. $3 a$ ), while those not preincubated could not (Fig. $3 b$ ). These findings indicate that, even if the primerindependent glucosyltransferase is a glycoprotein, the line stained by periodic acid Schiff was due to glucan synthesized by the enzyme, and not to glycosyl residues on the enzyme itself. It is probable that the antigenic sites on the primer-independent glucosyltransferase that were bound by the antiserum used in this study did not correspond to the active site of the enzyme, in which case it is unclear why the enzyme activity was partially inhibited.

\section{REFERENCES}

Beighton, D., Russell, R. R. B. \& Hayday, H. (1981). The isolation and characterization of Streptococcus mutans serotype $h$ from dental plaque of monkeys (Macaca fascicularis). Journal of General Microbiology 124, 271-279.

Bratthall, D. (1970). Demonstration of five serological groups of streptococcal strains resembling Streptococcus mutans. Odontologisk revy 21, 143-152.

Coykendall, A. L. (1977). Proposal to elevate the subspecies of Streptococcus mutans to species status, based on their molecular composition. International Journal of Systematic Bacteriology 27, 26-30.

Critchley, P., WoOd, J., SaXon, C. \& Leach, S. (1976). The polymerisation of dietary sugars by dental plaque. Caries Research 1, 112-129.

Fukui, K., Fukui, Y. \& MoriYama, Y. (1974). Some immunochemical properties of dextransucrase and invertase from Streptococcus mutans. Infection and Immunity 10, 985-990.

Fukui, K., Moriyama, T., Miyake, Y., Mizutani, K \& TanakA, O. (1981). Purification and properties of glucosyltransferase responsible for water-insoluble glucan synthesis from Streptococcus mutans. Infection and Immunity 37, 1-9.

Fukui, K., Kokeguchi, S., Kato, K., Miyake, Y., NOGAMI, R. \& MORIYAMA, T. (1983). Immunochemical properties of glucosyltransferase from Streptococcus mutans. Infection and Immunity 39, 762-766.

GibBONS, R. J. (1968). Formation and significance of bacterial polysaccharides in caries ethiology. Caries Research 2, 164-171.
Gibbons, R. J. \& Banghart, S. (1967). Synthesis of extracellular dextran by cariogenic bacteria and its presence in human dental plaque. Archives of Oral Biology 12, 11-24.

Gibbons, R. J. \& NygaARd, M. (1968). Synthesis of insoluble dextran and its significance in the formation of gelatinous deposits by plaque-forming streptococci. Archives of Oral Biology 13, 1249-1262.

Hanada, N. \& Takehara, T. (1987). Comparison of different water-soluble glucan synthases from Streptococcus mutans serotype $g$. Microbios 50, 147-152.

Hanada, N., Takehara, T. \& SaEki, E. (1987). Purification and characterization of a third glucosyltransferase from Streptococcus mutans serotype $g$. Journal of General Microbiology 133, 1351-1358.

Kametaka, S., Hayashi, S., Miyake, Y. \& Suginaka, H. (1987). Electrophoretic studies of extracellular glucosyltransferases and fructosyltransferases from seventeen strains of Streptococcus mutans. Archives of Microbiology 147, 207-212.

Kumada, H., Umemoto, T., Onisi, M., Tsumori, H., Shimamura, A. \& Mukasa, H. (1987). Purification and characterization of extracellular glucosyltransferase from Streptococcus mutans serotype $b$ (subspecies rattus). Journal of General Microbiology 133, 1435-1441.

LinzeR, R. \& SLADE, H. D. (1976). Characterization of an anti-glucosyltransferase serum specific for insoluble glucan synthesis by Streptococcus mutans. Infection and Immunity 13, 494-500.

MCCABE, M. M. (1985). Purification and characteriza- 
tion of a primer-independent glucosyltransferase from Streptococcus mutans 6715-13 mutant 27. Infection and Immunity 50, 771-777.

Mukasa, H. (1986). Properties of Streptococcus mutans glucosyltransferases. In Molecular Microbiology and Immunology of Streptococcus mutans, pp. 121-132. Edited by S. Hamada, S. M. Michalek, H. Kiyono, L. Menaker \& J. R. McGhee. Amsterdam, New York, Oxford: Elsevier.

OUCHTERLONY, O. (1958). Diffusion in gel methods for immunological analysis. Progress in Allergy 5, 1-9.

Perch, B., KJEMS, T. \& Ball, C. (1974). Biochemical and serological properties of Streptococcus mutans from various human and animal sources. Acta pathologica, microbiologica et immunologica scandinavica 82, 357-370.

Shimamura, A., Tsumori, H. \& Mukasa, H. (1982). Purification and properties of Streptococcus mutans extracellular glucosyltransferase. Biochimica et biophysica acta 702, 72-80.

ShKlair, I. L. \& KeENe, H. J. (1974). A biochemical scheme for the separation of the five varieties of Streptococcus mutans. Archives of Oral Biology 19, 1079-1081.

Takehara, T., Hanada, N. \& Saeki, E. (1984). Interaction of glucosyltransferase isozymes on glucan synthesis by Streptococcus mutans AHT (serotype g). Microbios Letters 27, 113-120. 